\title{
Recomendaciones en la pesquisa y diagnóstico de la displasia del desarrollo de las caderas
} Screening and diagnostic recommendations in the developmental dysplasia of the hip

\author{
Dra. A. Patricia Nally y Dra. Mónica A. Galeano
}

\section{RESUMEN}

La displasia del desarrollo de la cadera (DDC) es una anomalía de la articulación coxofemoral caracterizada por una laxitud o posicionamiento anormal de la cabeza femoral con respecto al acetábulo. Es la patología ósea perinatal más frecuente, e incluye alteraciones que van desde el aplanamiento o la displasia acetabular hasta una luxación completa de la cabeza femoral fuera de la articulación, que puede comprometer el desarrollo y la estabilidad articular. Nuestro objetivo es transmitir una sistemática de estudio en la valoración de la cadera del recién nacido, haciendo énfasis en un examen físico correcto como pilar fundamental en la detección de la DDC, y orientar al pediatra en la selección adecuada del método diagnóstico complementario acorde a edad del paciente, con el fin de optimizar la detección y reducir el número de caderas luxadas en etapas tempranas y tardías, y así disminuir la incidencia de patologías asociadas desarrolladas a partir de este trastorno.

Palabras clave: cadera, desarrollo, displasia congénita de la cadera, pesquisa, ecografía.

a. Hospital Interzonal Especializado Materno Infantil Don Victorio Tetamanti, Mar del Plata, Argentina.

b. Hospital de Pediatría S.A.M.I.C. Prof. Dr. Juan P. Garrahan, Ciudad Autónoma de Buenos Aires, Argentina.

Correspondencia:

Dra. A. Patricia Nally: a.patricianally@gmail. com.ar

Financiamiento:

Ninguno.

Conflicto de intereses: Ninguno que declarar.

Recibido: 17-2-2021

Aceptado: 23-2-2021

Participante en la elaboración del documento:

Dr. Luis F. Gentile

Colaboradores:

Comité Nacional de Diagnóstico por Imágenes

Secretaria: Dra. Mónica A. Galeano

Prosecretaria: Dra. Raquel E. Buttiero Dr. Guillermo A. Fernández y Dra. Paola S. Berra in the proper selection of the complementary diagnostic method to be used according to the age of the patient, in order to optimize detection and reduce the number of dislocated hips in early and late stages as well as the incidence of related pathologies.

Key words: hip, developmental, congenital hip dysplasia, screening, ultrasound.

http:/ / dx.doi.org/10.5546/ aap.2021.S159

Cómo citar: Nally AP, Galeano MA. Recomendaciones en la pesquisa y diagnóstico de la displasia del desarrollo de las caderas. Arch Argent Pediatr 2021;119(4):S159-S170.

\section{INTRODUCCIÓN}

La displasia del desarrollo de la cadera (DDC) es una anomalía de la articulación coxofemoral que se caracteriza por una laxitud o posicionamiento anormal de la cabeza femoral con respecto al acetábulo, e incluye un espectro de alteraciones que van desde el aplanamiento del acetábulo o displasia acetabular hasta una luxación completa de la cabeza femoral fuera de la articulación. Las alteraciones de la forma de la cabeza femoral y del acetábulo pueden comprometer el desarrollo y la estabilidad articular.

Dr. Gustavo M. Molteni, Dra. Cecilia E. Rey, Dra. María F. Mateos, Dr. Luis F. Gentile, 
Como muchos de estos hallazgos pueden aún no estar presentes al momento del nacimiento, se ha utilizado la terminología de "displasia del desarrollo" para reflejar, de manera más adecuada, el comportamiento biológico de esta patología más que un origen congénito. ${ }^{1}$

La DDC es la patología ósea perinatal más frecuente, con una incidencia que varía desde $1 / 1000$ recién nacidos vivos hasta el $6 \%$ acorde a la literatura. Se observa predominio de pacientes de sexo femenino, con una relación 6:1. El compromiso bilateral se observa en alrededor del $50 \%$ y, si es unilateral, afecta 3 veces más la cadera izquierda con respecto a la derecha, ${ }^{2}$ en el $95 \%$ de los casos son luxaciones posteriores.

El desarrollo de la cadera comienza dentro del útero y termina en la vida adulta; por lo tanto, la DDC puede ocurrir antes del nacimiento, en la época perinatal o durante la infancia. ${ }^{2}$ Es importante destacar que las caderas que son estables al nacimiento no necesariamente se desarrollarán como caderas normales, ${ }^{3}$ ya que los signos clínicos de DDC pueden aparecer tardíamente; por ello, resulta muy importante

FIgURA 1. Correlación de métodos diagnósticos: radiografía y ecografía. A: radiografía de pelvis de frente con reparos anatómicos de relevancia. Se observa el posicionamiento del cartilago trirradiado y la disposición de los huesos que lo conforman: ilion (1), isquion (2) y pubis (3). B: gráfica que simula el ingreso del haz de ultrasonido para comprender la correlación entre la radiografía y la ecografía. La gráfica demarca la orientación del ingreso del haz de ultrasonido proyectada en una radiografía de frente ampliada sobre la cadera izquierda que se correlaciona con el corte coronal de ultrasonido. C: corte coronal de ultrasonido. Se muestra una verticalización del corte coronal de ultrasonido para el entendimiento de la localización espacial con respecto a la radiografía de frente.
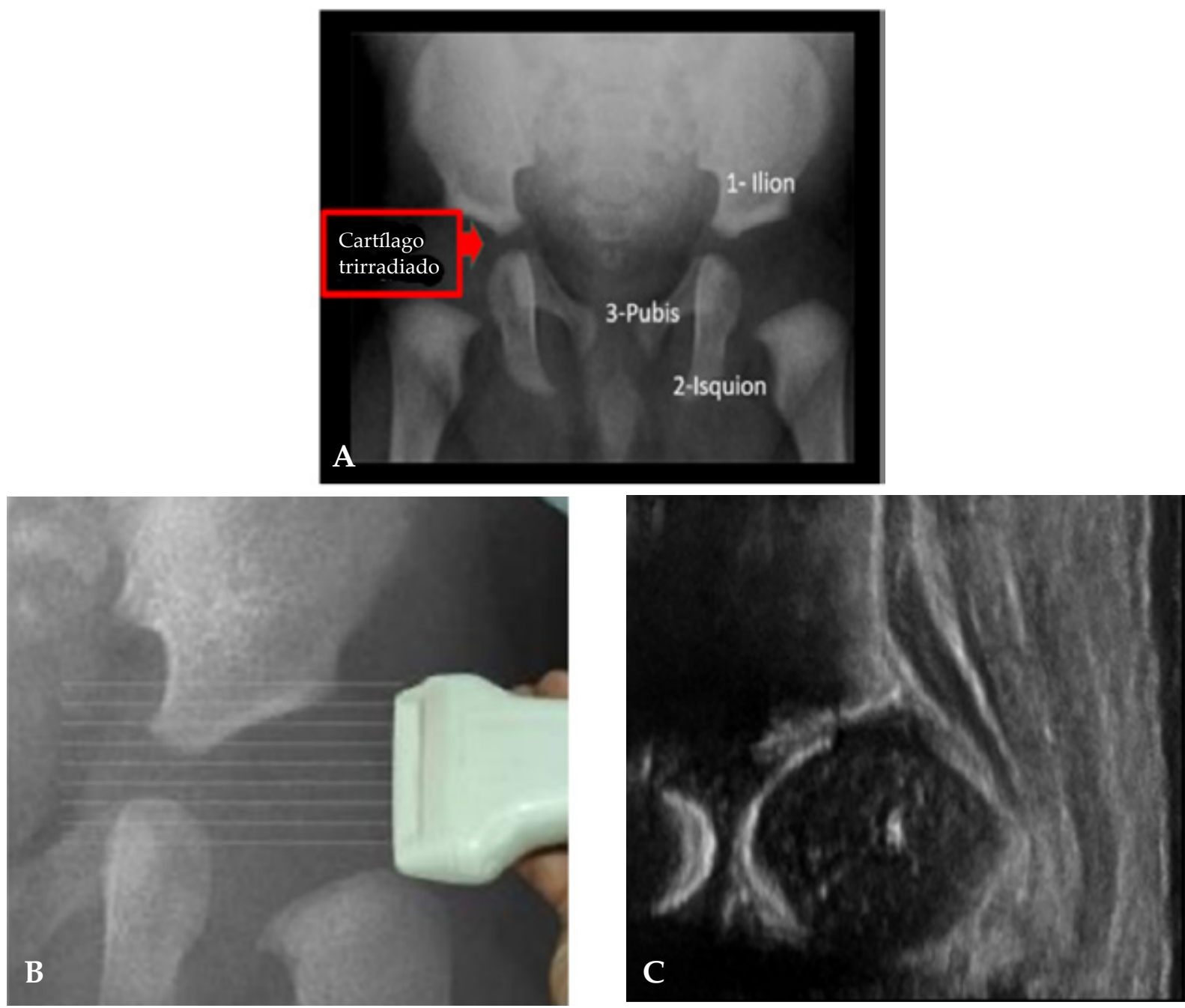
realizar el examen físico pediátrico en el período neonatal y en cada control mensual hasta los 12 meses de edad. ${ }^{4}$

Cuanto más temprano se detecte la luxación de la cadera, más simple y efectivo será el tratamiento. ${ }^{1}$ Hacemos énfasis en el examen físico correcto como pilar fundamental en la detección de la DDC y destacamos la propuesta de una pesquisa universal en el examen clínico a todo recién nacido, ${ }^{1}$ aunque hasta la fecha, hay poca literatura basada en evidencia.

\section{OBJETIVOS}

Esta presentación está dirigida a neonatólogos, pediatras y aquellos profesionales que atienden a niños, en especial a aquellos que ejercen la atención primaria de la salud, con el objetivo de transmitir una sistemática de estudio, con pautas recomendadas, que agilicen y optimicen la detección de la DDC.

La meta principal será reducir el número de caderas luxadas detectadas en etapas tempranas y tardías, y disminuir la incidencia de patologías asociadas desarrolladas a partir de esta.

Otro objetivo es orientar en la selección adecuada del método diagnóstico que se utilizará acorde a la edad del paciente, y facilitarle al profesional las herramientas necesarias para conocer los métodos diagnósticos complementarios que se detallan más adelante en las Figuras 1a, 1b y 1c (Correlación de métodos diagnósticos radiografía/ecografía) y la Figura 2, donde se muestra la anatomía básica mediante la ecografía de la cadera.

\section{Importancia del diagnóstico temprano de la DDC}

Es de fundamental interés resaltar la importancia de la anamnesis para la búsqueda de esta entidad, con un interrogatorio focalizado y orientado a la pesquisa de factores de riesgo. Con una mirada fisiopatológica, comprendemos que la relación anormal entre la cabeza femoral y el acetábulo hacen que la articulación no pueda transmitir correctamente las cargas a las que se somete. La sobrecarga mecánica acumulativa afectaría las estructuras articulares y podría llevar a una coxartrosis precoz, ${ }^{5}$ una artropatía degenerativa de la cadera que puede llegar a ser discapacitante. Los niños con DDC y una articulación acetabular hipoplásica, sumada a la deformación de la cabeza femoral, con frecuencia desarrollan una artrosis grave y progresiva en la adolescencia tardía o en la adultez temprana, ${ }^{5}$ que puede provocar múltiples efectos colaterales posteriores, como escoliosis, acortamiento de la

Figura 2. Anatomía básica en la ecografía de caderas. Corte coronal normal de la cadera con ultrasonido: localización de los músculos glúteos, el hueso ilíaco como una línea ecogénica (blanca) lineal horizontal, la cobertura cartilaginosa acetabular y el cartílago trirradiado acetabular como estructuras hipoecoicas (negras). Las flechas rojas indican los reparos que debemos reconocer

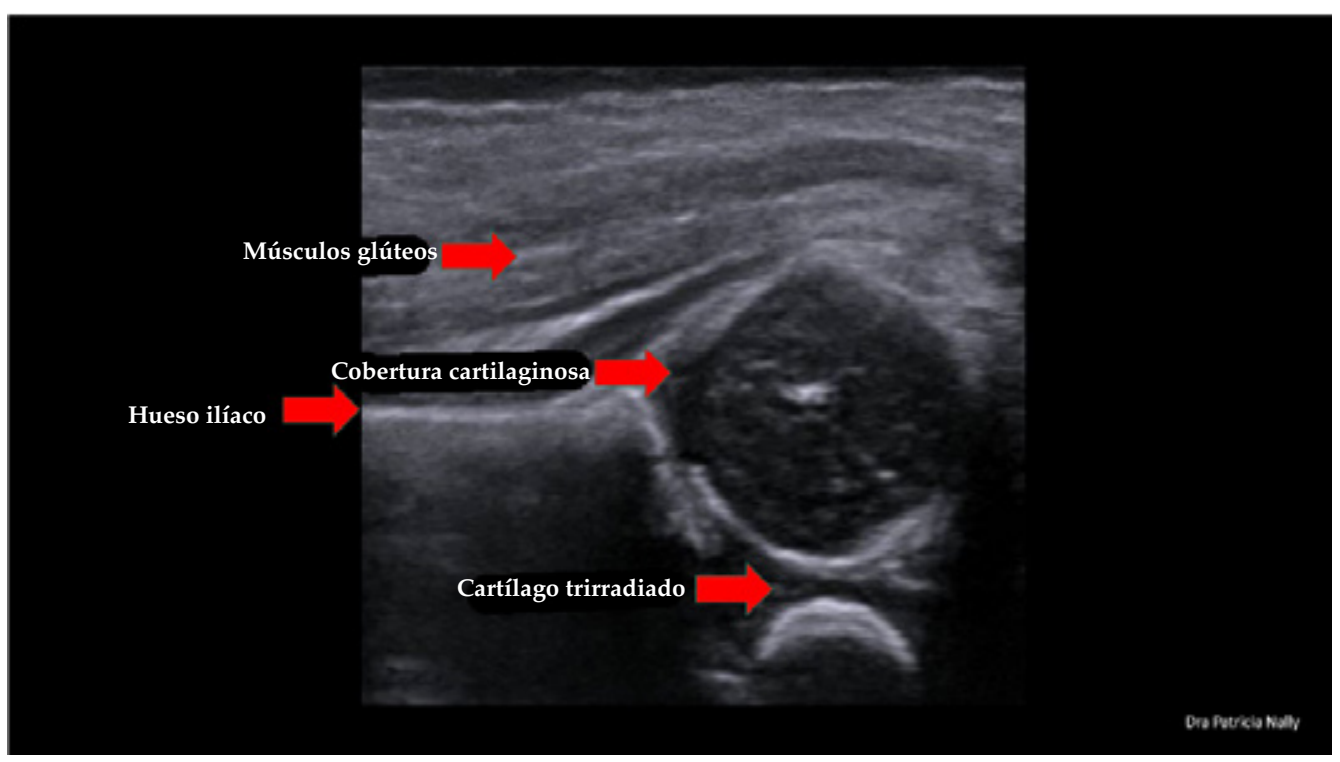


extremidad, deformidades en la rodilla y en la cadera contralateral, dolor crónico y limitación de la movilidad articular, con compromiso significativo de su calidad de vida.

\section{Definición y etiología}

La luxación de la cadera es la pérdida completa de contacto entre la cabeza femoral y el acetábulo. Puede dividirse en dos tipos: la primera, una luxación teratológica que ocurre en etapas tempranas de la vida intrauterina, frecuentemente asociada a trastornos neuromusculares como artrogriposis, mielodisplasia o diversos síndromes dismórficos; y la segunda, aquella que ocurre en el niño sin otra patología prenatal o posnatal. ${ }^{1}$ Se cree que factores fisiológicos, mecánicos y genéticos están implicados en la DDC, ${ }^{6}$ aunque en realidad se desconoce la etiología.

Existen posibles factores intrínsecos, como una disminución de la resistencia para la luxación, el acetábulo aplanado o la laxitud del tejido conectivo. También se detallan factores extrínsecos, como la posición dentro del útero, entre ellos el más significativo es el de situación podálica que se presenta en aproximadamente el $3 \%$ de los partos (25\% de riesgo).

Entre los factores mecánicos, que son aquellos asociados al espacio restringido en el útero, se encuentra la compresión mecánica con restricción espacial de los movimientos, que se acentúa en etapas tardías de la gestación, para tener en cuenta en el oligohidramnios, ${ }^{6}$ en el primer embarazo, en fetos macrosómicos y en el útero bicorne.

Otras condiciones asociadas a la constricción del útero se detallan más adelante.

\section{Prevalencia}

La prevalencia de la DDC es variable, según la literatura, y depende del método de pesquisa utilizado.

Barlow (1962) indicó que 1 de cada 67 recién nacidos presentaba inestabilidad de una o ambas caderas. El $60 \%$ adquirió estabilidad a la semana, y el $88 \%$ a los 2 meses. El $12 \%$ restante fueron luxaciones congénitas verdaderas. Este estudio enfatizó que la edad al momento de la examinación resulta fundamental. ${ }^{7}$ Detectó, por examen físico, que el 1,5\% de los 7742 recién nacidos que había estudiado tenían caderas dislocadas o dislocables en exámenes físicos cercanos al nacimiento. ${ }^{7}$ El seguimiento clínico y radiológico hasta el año de vida demostró una incidencia final de DDC del 0,15\%.

Como se mencionó, esta patología no siempre se detecta al nacimiento, ya que se han informado casos con pesquisa neonatal normal que luego evidenciaron DDC. Por esta razón, en todos aquellos niños con factores de riesgo se debería repetir el examen clínico y valorar la opción de un método complementario de imágenes. ${ }^{3}$

\section{Factores anatómicos para tener en cuenta}

La DDC es un cuadro dinámico que se produce por la inestabilidad de la articulación coxofemoral del recién nacido.

El cartílago trirradiado se forma del isquion, pubis e ilion. El crecimiento estable y equitativo de los tres huesos va a mantener la conformación esférica del cotilo y de la cabeza femoral.

La presión que la cabeza femoral ejerce sobre el acetábulo en la etapa fetal contribuye a su conformación en bóveda. Si la cabeza saliera del acetábulo, esta no crecería de manera esférica y se aplanaría. ${ }^{2}$

En la etapa posnatal, el acetábulo continúa su desarrollo a través del crecimiento del rodete fibrocartilaginoso (labrum) que rodea el acetábulo óseo, haciendo más profunda esta cavidad.

El ángulo cérvico-cefálico de la cabeza del fémur es mayor en el recién nacido $\left(150^{\circ}\right)$, lo que favorece la luxación perinatal.

\section{Riesgos del desarrollo de la cadera dentro del útero $\mathrm{y}$ perinatal}

La cadera está en peligro de luxarse en 4 períodos: en las semanas 12 y 18 de gestación, en las últimas 4 semanas previas al nacimiento y en el período posnatal. ${ }^{1}$

Alrededor de la semana 11 de gestación, se constituye la articulación coxofemoral y la cabeza femoral crece más rápido que el acetábulo, lo que determina una menor cobertura de la cabeza por parte del acetábulo.

En la semana 12, hay una rotación medial de las extremidades inferiores, situación que también favorece la dislocación.

A la semana 18, se desarrollan los músculos de la cadera y es cuando pueden evidenciarse las alteraciones neuromusculares con riesgo de luxación (llamada luxación teratológica, ocurre en el $2 \%$ de los pacientes con displasia de cadera).

En las últimas 4 semanas de gestación, reaparece el riesgo de luxación debido a los factores mecánicos relacionados con la posición podálica o al oligohidramnios.

La flexión extrema durante el parto causaría contracción del iliopsoas e induce a una posterior dislocación. 
Las hormonas maternas cerca del parto causan una laxitud transitoria y fisiológica de la articulación de la cadera. ${ }^{6}$

\section{Recomendaciones en la detección de la población de riesgo \\ Examen físico dirigido}

El examen clínico que permite realizar esta pesquisa a los niños es fundamental para hacer un diagnóstico temprano en la mayoría de los pacientes. Deben valorarse la asimetría de pliegues cutáneos, la asimetría de la longitud de las extremidades, la limitación en la abducción y la presencia de chasquidos audibles durante la realización de las maniobras (maniobra de Ortolani y maniobra de Barlow + ). Este examen requiere habilidad y paciencia. Se considera que es operador dependiente, ya que, si el pediatra se enfoca en la pesquisa de asimetría, corre el riesgo de pasar por alto una alteración bilateral. Los signos clínicos pueden estar ausentes en pacientes con displasia acetabular sin luxación. ${ }^{1}$ Primero, debemos buscar una limitación de abducción (se aleja de la línea media del cuerpo) y flexionar ambas caderas buscando un ángulo de $90^{\circ}$ para luego permitir un movimiento suave de apertura. La asimetría se detecta comparando la amplitud del movimiento de cada cadera y evaluando el grado de resistencia entre los dos lados con un aumento gradual y delicado de la abducción.

En la maniobra de Barlow, una mano estabiliza la pelvis mientras la otra sostiene la rodilla y flexiona la cadera formando un ángulo de $90^{\circ}$; los dedos de esa mano deben colocarse por encima del trocante mayor y aducir (aproximar a la línea media) la cadera de $10^{\circ}$ a $20^{\circ}$ aplicando una presión suave. Se debe detectar un clic correspondiente a la cabeza del fémur que se desplaza del borde del acetábulo.

En la maniobra de Ortolani, se deben flexionar ambas piernas y caderas hasta $90^{\circ}$. El pulgar sostiene la parte interna de la rodilla mientras que

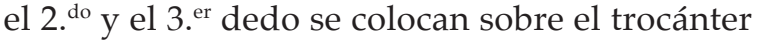
mayor abduciendo la cadera en forma paulatina mientras los dedos intentan introducir la cabeza dislocada del fémur dentro del acetábulo. Si se oye un clic, será porque la cadera se redujo.

Anamnesis focalizada en la detección de factores de riesgo 1. Antecedentes familiares de displasia de cadera: hay una predisposición genética asociada al riesgo de DDC, que aumenta el $6 \%$ con la existencia de un hermano con dicha patología y padres sin antecedentes. Con un progenitor comprometido, las probabilidades aumentan el $12 \%$, y ambas situaciones sumadas elevan el riesgo al $36 \%{ }^{8}$

Se toma como promedio que el $20 \%$ de pacientes que poseen antecedentes familiares podrían desarrollar una DDC.

2. Primigesta, oligohidramnios y presentación podálica: entre el $30 \%$ y el $50 \%$ de los niños con presentación podálica desarrollarían DDC por influencia en la postura de las caderas dentro del útero. Se ha informado que el $16 \%$ de los niños con DDC habrían tenido dicha presentación dentro del útero, con caderas en flexión y rodillas en extensión. ${ }^{9}$

3. Síndromes de hiperlaxitud articular: síndrome de Ehlers Danlos y síndrome de Down.

4. Malformaciones posicionales: condiciones asociadas a la constricción del útero, como tortícolis congénita asociada a fibromatosis colli; deformidades de los pies, como pie bot, metatarso aducto; escoliosis y deformaciones por moldeamiento de la bóveda craneal, como plagiocefalia, entre otras, tienen una vinculación mayor con la DDC. ${ }^{6}$

5. Malformaciones congénitas esqueléticas: artrogriposis, escoliosis, mielomeningocele y síndrome de regresión caudal se encuentran asociados a la displasia de cadera teratológica. Es una categoría especial de luxación en recién nacidos con un trastorno neuromuscular subyacente en el que la cadera se luxa en etapas tempranas de la gestación y causa cambios acetabulares y femorales significativos. ${ }^{6}$ Como se mencionó, conforman un porcentaje pequeño, pero son las más difíciles de tratar. ${ }^{10}$

\section{Utilización de imágenes diagnósticas} complementarias a la evaluación clínica

A. Ecografía estática y dinámica (Figura 3).

B. Radiografía (Figura 4).

C. Resonancia magnética.

\section{A. Utilización de la ecografía}

¿Por qué realizar una ecografía de caderas?

La ecografía es un método no invasivo que permitió mejorar la especificidad y sensibilidad sin radiación ionizante. Es un estudio de rápida realización y bajo costo. Habilita un diagnóstico más temprano que la radiografía, con gran detalle anatómico de estructuras osificadas y cartilaginosas. La ecografía muestra los componentes cartilaginosos de la cabeza femoral, del acetábulo, el rodete y la cápsula articular. ${ }^{6}$ 
Figura 3. Ecografía de caderas con maniobras estáticas y dinámicas. A: ecografía estática (corte coronal y axial o transversal de la cadera). Estudio ecográfico estático realizado con maniobras de abducción, de características normales, que permiten focalizar la morfología del acetábulo y la cobertura de la cabeza femoral. B: ecografía dinámica (corte coronal). Izquierda: ecografía estática corte coronal. Derecha: estudio de ecografía dinámica, en corte coronal, realizado bajo maniobras de estrés de la cadera o maniobra de Barlow, donde se demuestra laxitud cefálica femoral. C: ecografía de caderas patológica. Corte coronal por ultrasonido de la cadera izquierda que demuestra luxación posterior de la cabeza femoral con déficit de cobertura acetabular y tejido interpuesto en la proyección articular coxofemoral que imposibilita la reubicación de la cabeza en su fosa acetabular.
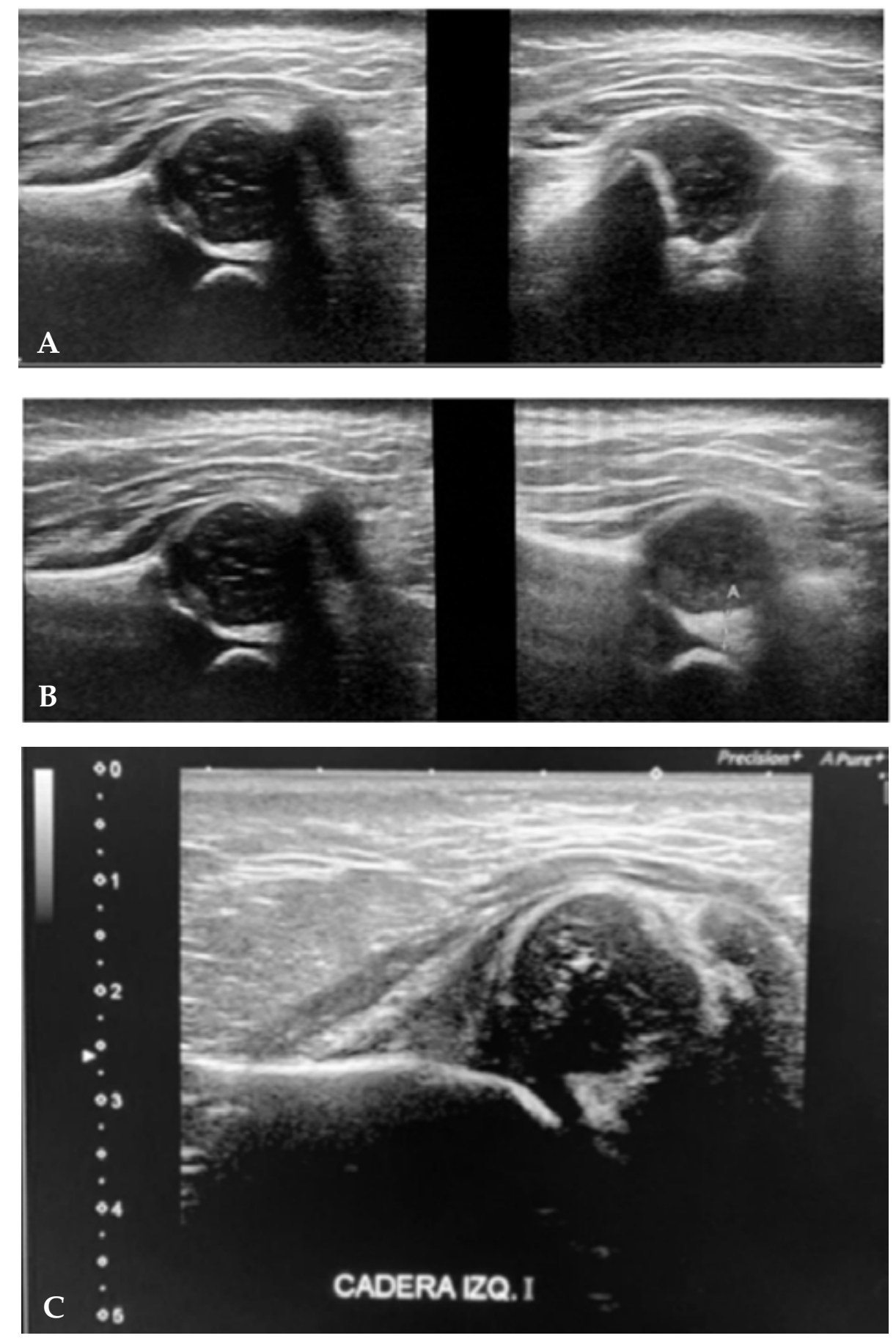
Permite valorar la evolución de los núcleos de osificación de la epífisis femoral y su simetría. Si estos se demoraran en aparecer después del año de vida, es importante el seguimiento con radiografía para el control de los casos de DDC de aparición tardía. ${ }^{11} \mathrm{Ha}$ sido considerada el método más preciso en la evaluación de las caderas durante los primeros meses de vida, dado que permite visualizar la cabeza femoral cartilaginosa, caracterizar el acetábulo y evaluar la presencia de inestabilidad. ${ }^{12,13}$ Permite también la evaluación multiplanar, axial (en un plano de sección transversal de la articulación) y coronal (en un plano de sección frontal), ${ }^{14} \mathrm{y}$ posibilita un examen estático y dinámico en tiempo real.

Es posible, además, visualizar la respuesta a las maniobras clínicas universales en tiempo real, la maniobra de Barlow (para determinar si la cadera es luxable) con maniobras de estrés y la maniobra de Ortolani (para determinar si la cadera es reductible). Es un estudio repetible, por lo cual facilita el control evolutivo del tratamiento. La ecografía presenta una sensibilidad de entre el $90 \%$ y el $95 \%$, y una especificidad de alrededor del $90 \% ;^{14}$ para lograrlo, es importante que el estudio sea realizado por un especialista entrenado en la práctica de la ecografía de caderas.

FIGURA 4. Radiografía de caderas frente. A: radiografía de características normales. B: cuadrantes de Ombredanne en radiografía de cadera sin núcleos cefálicos femorales visibles. Medidas ortopédicas: línea P vertical de Perkins (azul), línea horizontal de Hilgenreiner (amarillo), linea S arcada de Shenton (doble línea), línea A que demarca el ángulo acetabular (rojo). Radiografía de caderas dentro de limites normales. C: cuadrantes de Ombredanne en radiografía de cadera con núcleos cefálicos femorales visibles. Medidas ortopédicas: línea P vertical de Perkins (azul), línea horizontal de Hilgenreiner (amarillo), línea S arcada de Shenton (doble línea), línea A que demarca el ángulo acetabular (rojo). Se evidencian núcleos de osificación en cuadrante inferomedial. Radiografía de características normales. D: radiografía de caderas patológica de pelvis frente. Se observa lateralización y ascenso femoral, con aplanamiento del techo acetabular y formación de un neoacetábulo. Hay ausencia de núcleo de osificación femoral de cadera derecha; se visualiza el de la cadera izquierda de características normales. Las imágenes son compatibles con luxación de la cadera derecha. E: radiografía de pelvis de frente. Se demuestra control evolutivo del mismo paciente de la figura 4D. Se observa desarrollo normal del núcleo de osificación femoral de la cadera izquierda con evolución adecuada con respecto a radiografía previa, persistiendo la ausencia del núcleo de osificación de la cadera derecha. Los hallazgos son compatibles con respuesta desfavorable al tratamiento ortopédico. F: Radiografía de caderas con patología bilateral.

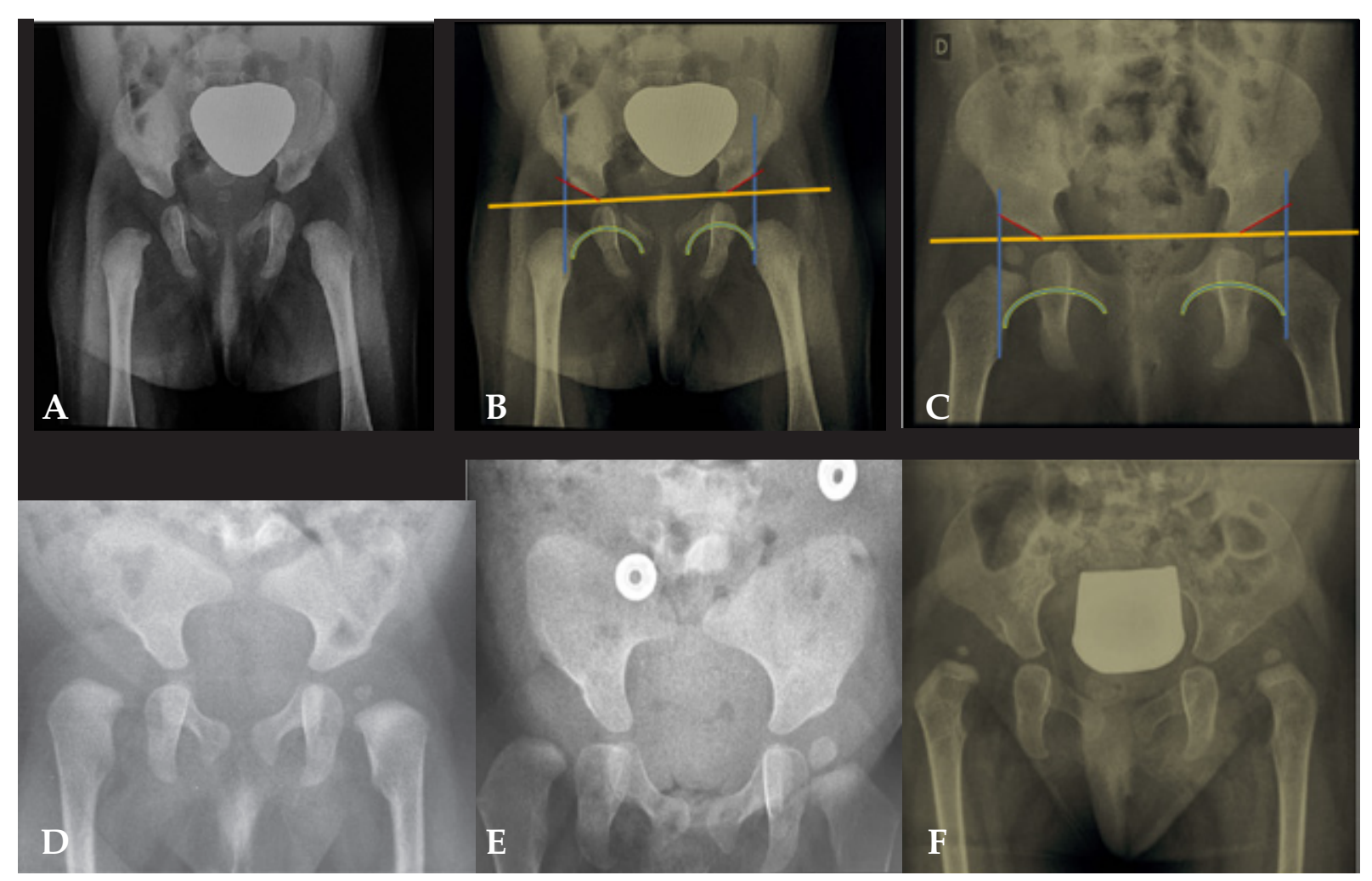


Limitaciones de la ecografía

La elección de la ecografía de caderas como método complementario de imágenes dependerá de si se tiene "accesible a un especialista en diagnóstico por imágenes pediátrico, entrenado especialmente en dicha práctica". Así lo recomienda en su protocolo el Consejo Médico Asesor del Instituto Internacional de Displasia de Caderas (Figura 5). El tamaño o el peso del paciente pueden imposibilitar la realización correcta de la ecografía. Superados los 6 meses de vida, resulta complicado realizar un posicionamiento correcto, así como objetivar las maniobras dinámicas requeridas en la ecografía.

Hay que tener en cuenta la interposición de los núcleos de osificación de la epífisis femoral que impedirían valorar el cartílago trirradiado y la cobertura acetabular. Estos núcleos comienzan a verse por ecografía de 2 a 4 semanas antes que en la radiografía. Pueden ser inicialmente asimétricos; a los 5 meses de edad están presentes en el $60 \%$ de los pacientes; a los 7 meses, en el $86 \%$, y a los 9 , en el $97 \%$.

El valor de la ecografía disminuye a medida que la cabeza femoral se osifica, ${ }^{15}$ pero, en general, se puede realizar hasta $\operatorname{los} 6$ a 8 meses de edad, acorde a la madurez esquelética de cada niño.

\section{¿A qué pacientes se recomienda realizar una ecografía de caderas?}

Se considera como indicación absoluta o consensuada por el Instituto Americano de Ecografía en Medicina (2018) la realización de la ecografía tras un examen físico anormal con visualización de asimetría de pliegues, acortamiento de miembros, limitación en la abducción, signos de inestabilidad clínica en las maniobras de exploración (maniobras de Barlow / Ortolani positivas), en pacientes de grupos de riesgo -historia familiar de DDC, presentación podálica, condiciones neuromusculares- y en el monitoreo de pacientes bajo tratamiento. ${ }^{15}$

FiguRa 5. Recomendaciones del Consejo Médico Asesor del Instituto Internacional de Displasia de Cadera (diciembre de 2015). El gráfico determina los pasos por seguir según el examen físico del niño sea normal o patológico, teniendo en cuenta la edad del paciente y factores de riesgo. Se hace énfasis en la accesibilidad a personal capacitado en ecografía, lo cual determinará la elección del método de imágenes complementario para llegar al mejor diagnóstico.

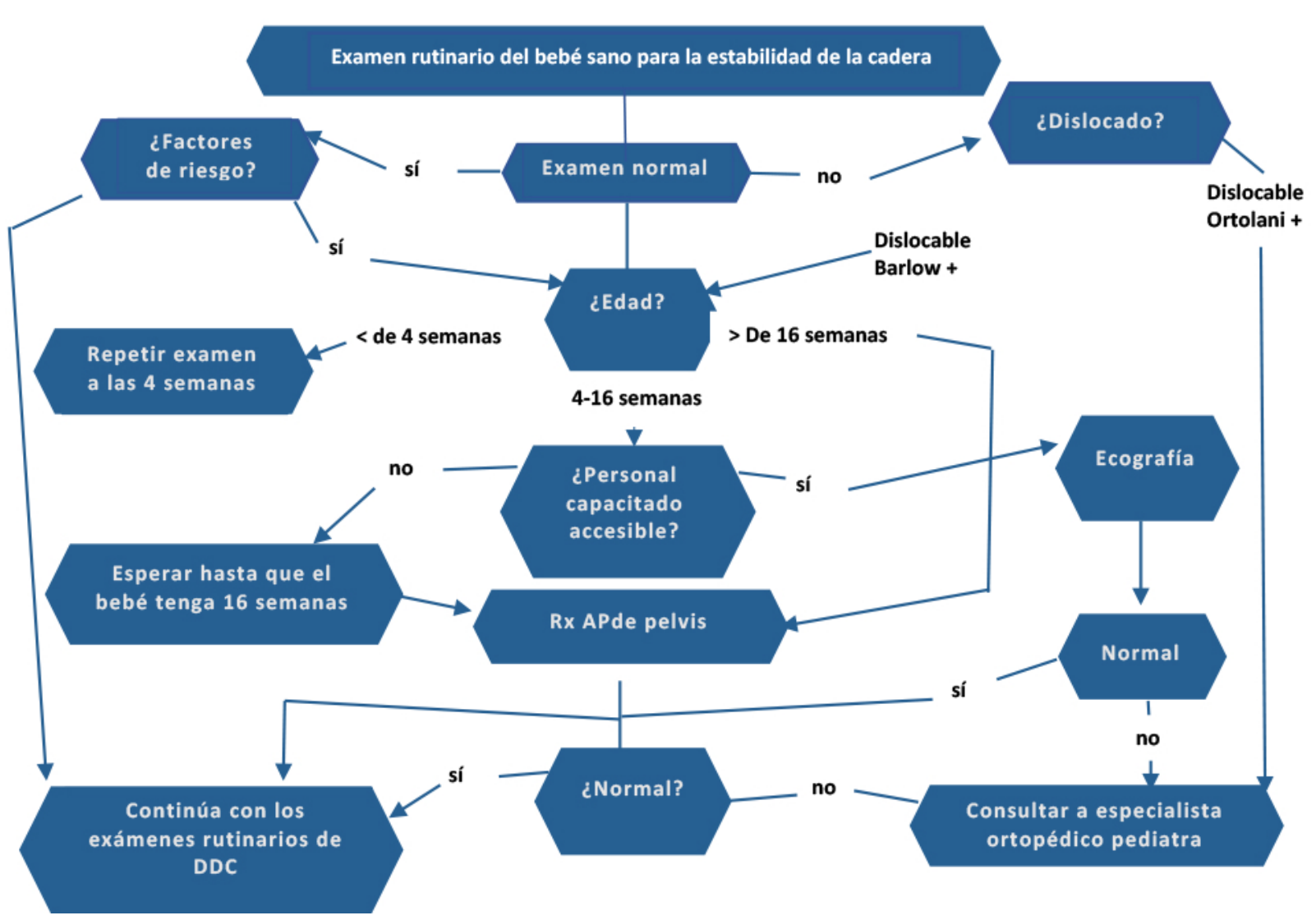


Indicaciones relativas son el oligohidramnios y otras causas de deformación postural dentro del útero, ${ }^{15}$ como pie varo, pie talo, pie valgo, tortícolis, y también el hallazgo de alguna pesquisa de patología en recién nacidos. ${ }^{14}$

\section{¿Cuándo se recomienda solicitarla?}

Es el método de elección en menores de 4 meses, cuando el núcleo de osificación es una estructura cartilaginosa.

En la mayoría de los recién nacidos, podemos encontrar una laxitud ligamentaria normal provocada por los estrógenos maternos, que puede ser la causa de un falso positivo en las primeras semanas de vida. Debido a la laxitud fisiológica de la cadera, la ecografía no debería realizarse en menores de 6 semanas. ${ }^{15}$ No se recomienda su realización antes de las 2 semanas, excepto que esta sea inestable clínicamente o se encuentre luxada. Si el examen físico es dudoso o hay factores de riesgo, sería recomendable realizar una ecografía entre las 2 y las 4 semanas de vida, ${ }^{2}$ y a las 6 semanas de vida. ${ }^{1}$

\section{Requerimientos importantes del estudio ecográfico} para permitir una toma de decisión

1. La ecografía de caderas debe ser realizada por un ecografista especialmente entrenado en dicha práctica, más allá de las bases teóricas. H. T. Harcke, el inventor de la evaluación dinámica de las caderas, recomienda realizar al menos 100 ecografías de caderas para considerarse capacitado para utilizar esta modalidad diagnóstica. ${ }^{16} \mathrm{El}$ examen requiere una evaluación de la relación de la cabeza femoral con el acetábulo en dos planos ortogonales, vista coronal y vista transversal de la cadera flexionada en reposo y durante las maniobras de estrés (posición y estabilidad). ${ }^{6}$

2. El estudio ecográfico debe mostrar detalles necesarios para poder tomar una decisión terapéutica junto con el examen físico. Existen dos escuelas diferentes para la valoración de la DDC: la modalidad de Graf (Austria) posee un método de examen estático, basado en la medición de ángulos. El método de Harcke (Estados Unidos) incorpora el estudio dinámico en la evaluación de la cadera.

Es de amplia difusión la técnica de Rosendhal, una modalidad intermedia entre ambas, que incorpora la medición del ángulo alfa al estudio dinámico de Harcke. Las medidas estándares utilizadas para detectar y diagnosticar la DDC incluyen el ángulo alfa y el porcentaje de cobertura de la cabeza femoral. ${ }^{17}$ El ángulo alfa proporciona una medida de la profundidad del acetábulo (formado entre el techo del acetábulo y la corteza vertical del ilion), ${ }^{17} \mathrm{y}$ debe ser mayor de $60^{\circ}$ para considerarlo normal. ${ }^{6} \mathrm{El}$ porcentaje de cobertura de la cabeza femoral demuestra el grado en que la cabeza femoral está contenida dentro del acetábulo.

Posición de la cabeza femoral: este punto se clasificará en relación con la posición de la cabeza en el acetábulo y podrá discernir entre una cadera centrada, cadera subluxada o cadera luxada.

Cobertura ósea: una cabeza femoral normalmente posicionada tiene una cobertura del acetábulo mayor al $50 \%$ (cobertura ósea adecuada). Resulta deficiente si disminuye su porcentaje. Si se encuentra aplanado o con menor cobertura para la cabeza femoral, podemos pensar en DDC.

Cobertura cartilaginosa: puede ser adecuada o deficiente, pudiendo encontrarse evertida o interpuesta entre la cabeza femoral y el acetábulo.

Núcleos de osificación: pueden estar ausentes o presentes, y ser simétricos o asimétricos.

3. El estudio dinámico determina si la cadera es estable o inestable. Se deben considerar los siguientes posibles escenarios:

- Si la cadera no está luxada, permite valorar diferentes grados de laxitud con maniobras dinámicas de estrés (maniobra de aducción de la cadera o Barlow bajo control ecográfico). No se debe realizar esta maniobra de estrés en una cadera luxada.

- Si la cadera está luxada o subluxada, permite determinar si es reductible o irreductible (maniobras de abducción de la cadera u Ortolani bajo control ecográfico).

- Recordar que la cadera puede ser subluxable con movimientos espontáneos del niño.

- Monitoreo con arnés de Pavlik: luego de la colocación del arnés, se realizan ecografías seriadas para valorar la respuesta al tratamiento; el arnés debe estar puesto. Es importante recalcar que no deben realizarse maniobras de estrés en la cadera con arnés de Pavlik. ${ }^{18}$

- Evaluación con ecografía doppler color: útil en algunas oportunidades para estimar la perfusión de la epífisis proximal femoral ante la sospecha de necrosis ósea avascular. ${ }^{18}$ 


\section{¿La pesquisa con ecografía es causa de sobrediagnóstico?}

El examen clínico, con las maniobras de Ortolani y de Barlow, continúa siendo el método primario de diagnóstico de la DDC. ${ }^{12}$ La pesquisa ecográfica en recién nacidos detecta niños con laxitud transitoria o inmadurez acetabular, muchos de los cuales podrán tener caderas normales en pocas semanas. ${ }^{16}$ La utilización clínica de la pesquisa neonatal con ecografía habría resultado en un aumento de la incidencia de falsos positivos, permitiendo al pediatra establecer un diagnóstico temprano a menor edad, pero fallando en reducir la incidencia de la DDC tardía. ${ }^{2}$ Sería cuestionada porque aumentaría la tasa de tratamientos y seguimiento de pacientes sin significancia clínica, con respecto al cribado clínico solo, sin una reducción significativa de la prevalencia de luxación o subluxación tardías. Con el aumento de la tasa de tratamientos, habría un subsecuente aumento del riesgo de necrosis del núcleo de osificación femoral debido a la utilización innecesaria del arnés (del 2,5\% al $5 \%$ de los tratados). Los argumentos a favor de una pesquisa universal con ecografía han demostrado que caderas clínicamente silentes pueden ser displásicas y requerir cirugía. Las pruebas clínicas por sí solas tienen el riesgo de perder esta posibilidad diagnóstica. ${ }^{18}$ Hay algunos países donde se utilizan satisfactoriamente estos programas, como Alemania, Holanda, Polonia y Suiza.

Es sabido que la examinación clínica avezada dentro de las primeras 24 horas de vida requiere un entrenamiento y una experiencia no siempre accesibles en todos los medios, por lo que la ecografía reforzaría el diagnóstico inicial. ${ }^{19}$ Es por eso que, a pesar de las controversias y la falta de uniformidad en la literatura, la mayoría coincide en la utilidad de una pesquisa con imágenes para disminuir la prevalencia de displasia con luxación. ${ }^{13}$ Es indudable la importancia de la evaluación con ecografía para el diagnóstico temprano de la DDC. Sin embargo, el debate aún no está resuelto a nivel mundial, aún no se puede determinar si esta pesquisa debe realizarse en toda la población de recién nacidos (universal) ${ }^{19}$ o debe ser utilizada en grupos determinados (selectiva).

El déficit técnico en la realización del estudio ecográfico repercute en la obtención de diagnósticos no satisfactorios, tanto por el infradiagnóstico como por el sobrediagnóstico. Para brindar un servicio de pesquisa ecográfica satisfactoria, ${ }^{20}$ es necesario, como paso inicial, mejorar la accesibilidad al método y la formación específica en ecografía de caderas, para lo cual se requiere un programa de entrenamiento acreditado en la detección temprana de la displasia de las caderas.

\section{B. Utilización de la radiografía}

¿Cuándo debemos solicitar una radiografía?

La radiografía ha sido tradicionalmente utilizada en la evaluación de pacientes con DDC. Por la naturaleza cartilaginosa de la cabeza femoral hasta los 4-6 meses, su valor ha sido considerado limitado en el diagnóstico temprano, a pesar de su amplia disponibilidad y bajo costo, y se reserva su uso para el diagnóstico en lactantes de 6 meses de edad o más, y para el seguimiento de pacientes en tratamiento. ${ }^{1,13}$ Mientras haya una ventana acústica adecuada, se debería intentar realizar ecografía, si eso fuera posible. Cuando la osificación de las epífisis femorales se interpone en la evaluación y nos impide la correcta valoración con ecografía, debemos solicitar la radiografía, método más certero después de los 6 meses.

Es una responsabilidad pediátrica primaria la solicitud de la radiografía de caderas de manera correcta. Se solicita así: "Radiografía de ambas caderas frente con miembros inferiores extendidos y rodillas al cenit con protección gonadal".

- Medidas ortopédicas para tener en cuenta en la radiografía. El cótilo debe ser cóncavo y osificado correctamente en una disposición horizontal con un ángulo acetabular normal en el recién nacido alrededor de $30^{\circ}$, horizontalización hasta $22^{\circ}$ hacia el año de edad y $0^{\circ}$ a los 4 años ${ }^{21}$ (Figuras $4 a$ y $4 b$ ).

- Angulo acetabular A formado por el cruce de líneas horizontal de Hilgenreiner se traza entre los cartílagos trirradiados o de los acetábulos $\mathrm{H}$ y la tangente del techo acetabular o cótilo.

- La intersección con la línea perpendicular vertical de Perkins, en el borde externo del acetábulo, divide la cadera en cuatro cuadrantes. El núcleo femoral y el centro de la epífisis deben estar en el cuadrante inferomedial.

- Línea de Shenton: línea arcada continua, resultante de la unión del contorno metafisario medial del fémur con el borde inferior de la rama púbica superior.

Debe tenerse en cuenta que una rotación del paciente al momento de la exposición puede alterar la interpretación correcta de la 
radiografía. ${ }^{14}$ Se ha informado en la literatura la mayor densidad del techo acetabular sobre la foseta, interpretada como el impacto ejercido por la cabeza femoral cartilaginosa, por lo que no sería necesario esperar que esta osifique para determinar su localización, tomándose una foseta acetabular central como hallazgo cardinal. ${ }^{13}$

Cuando la cadera se encuentra fuera de lugar o luxada, el fémur asciende y se lateraliza con discontinuidad en la arcada de Shenton y posicionamiento anormal del núcleo femoral (Figura 4c).

\section{Utilización de la resonancia magnética}

Esta modalidad diagnóstica se reserva para casos más complejos debido a su mayor costo y requerimiento de sedación. Es de especial utilidad para determinar la interposición de tejidos blandos en la luz articular de aquellas caderas que no logran reducirse, como ligamentos, tendón del iliopsoas o hipertrofia del pulvinar o lábrum, También es solicitada en la evaluación de pacientes posquirúrgicos y ante la sospecha de necrosis ósea avascular, en que se utiliza administración de gadolinio para valorar la vascularización de la cabeza femoral. ${ }^{18}$

\section{CONCLUSIONES}

La DDC es una entidad clínica con un espectro de deformidades que varía desde una ligera incongruencia entre la superficie articular coxofemoral, que traerá un desgaste prematuro de dicha articulación, hasta la situación más grave, cuando la cabeza femoral está fuera del acetábulo. Es una patología dinámica que puede ocurrir durante la etapa prenatal o la posnatal, por lo que en los pacientes con factores de riesgo se deberá hacer un seguimiento exhaustivo. El examen clínico debe ser realizado siempre y es fundamental un examen físico dirigido (maniobras de Ortolani y de Barlow en búsqueda de limitaciones en la abducción, asimetrías de longitud de miembros o pliegues tanto glúteos como inguinocrurales). El interrogatorio deberá estar orientado a dichos factores de riesgo, en especial relacionados al sexo femenino, historia familiar de DDC, embarazo múltiple, presentación podálica, deformidades asociadas a factores mecánicos o posicionales dentro del útero, y otros síndromes asociados.

Los estudios de imagen deben complementar el examen clínico: la combinación de ambos podría considerarse el modelo diagnóstico ideal. ${ }^{17}$

La ecografía realizada por un especialista entrenado en displasia de caderas es la técnica ideal e inicial de elección para valorar la anatomía según la edad y para establecer, si lo tuviera, el grado de displasia, siempre teniendo en cuenta que es un estudio operador dependiente. Además, permite realizar un seguimiento en las caderas laxas hasta que maduren y progresen a la estabilidad, y determinar un diagnóstico temprano, control y seguimiento del tratamiento de la DDC con y sin tratamiento ortopédico. ${ }^{6}$

Si la ecografía fuera inaccesible o no permitiera un diagnóstico claro, puede realizarse la radiografía después de los 3 meses.

Es importante recordar que existen casos informados con examen físico e imágenes normales a los 3 meses de vida que luego han evidenciado DDC y que han sido considerados como displasia de presentación tardía. ${ }^{11,22}$

El resultado de programas de pesquisa ha indicado que 1 en 5000 niños tiene una cadera luxada detectada a los 18 meses o más. ${ }^{1}$ Debemos tener presente que la DDC altera la biomecánica de la cadera, con sobrecarga del cartílago articular, llevándola a una coxartrosis temprana, una de las principales causas de reemplazo total de cadera en el adulto joven, que llega al 21-29 \%. ${ }^{23}$ Todos los niños deberían ser examinados y diagnosticados por especialistas con la experiencia requerida para ello, utilizando la mejor tecnología posible a su alcance. ${ }^{24}$

Cuando se diagnostica la DDC de manera oportuna y por personal calificado, tiene un pronóstico favorable para la función motora y la calidad de vida, de allí la importancia de su diagnóstico temprano, que permitirá un tratamiento más exitoso y menos invasivo. El tratamiento temprano es crítico para proporcionar el mejor resultado funcional posible. ${ }^{17}$

\section{REFERENCIAS}

1. Committee on Quality Improvement, Subcommittee on developmental Dysplasia of the Hip. American Academy of Pediatrics. Clinical Practice Guideline: Early Detection of Developmental Dysplasia of the Hip. Pediatrics. 2000; 105(4 Pt 1):896-905.

2. Aronsson DD, Goldberg MJ, Kling TF Jr, Roy DR. Developmental dysplasia of the hip. Pediatrics. 1994; $94(2$ Pt 1):201-8. Erratum in: Pediatrics. 1994; 94(4 Pt 1):470.

3. Davies SJ, Walker G. Problems in the early recognition of hip dysplasia. J Bone Joint Surg Br. 1984; 66(4):479-84.

4. Roof A, Jinguji TM, White KK. Musculoskeletal screening: developmental dysplasia of the hip. Pediatr Ann. 2013; 42(11):229-35.

5. GanzR, Leunig M, Leunig-GanzK,Harris W. The etiology of osteoarthritis of the hip: an integrated mechanical concept. Clin Orthop Relat Res. 2008; 466(2):264-72.

6. Ladino Torres MF, Di Pietro M. Developmental Dysplasia of the Hip. Ultrasound Clin. 2009; 4(4):445-55 $\square$. 
7. Barlow TG. Early diagnosis and treatment of congenital dislocation of the hip. J Bone Joint Surg Br. 1962; 44(2):292301.

8. Wynne-Davies R. Acetabular Dysplasia and family joint laxity: two etiological factors in congenital dislocation of the hip. A review of 589 patients and their family. J Bone Joint Surg $\square \square$ Br. 1970; 52(4):704-16.

9. Muller GM, Seddon HJ. Late results of treatment of congenital dislocation of the hip. J Bone Joint Br. 1953; 35(3):342-62.

10. Stanisavljevic S. Etiology of congenital hip pathology. Part II: Anatomy of congenital hip pathology. In: Tachdjian MO, ed Congenital Dislocation of the Hip. New York: ChurchillLivingstone; 1982.Págs.27-57.

11. Tönnis D, Remus W. Development of hip dysplasia in puberty due to delayed ossification of femoral nucleus, growth plate and triradiate cartilage. J Pediatr Orthop B. 2004; 13(5):287-92.

12. Moloney F, Twomey M, Moore M. Pediatric ultrasound for developmental dysplasia of thehip: an educational pictorial review. ESSR 2014. Annual Congress of the European Society of Musculoskeletal Radiology. 26-28 june 2014. Riga, Latvia. Poster Number P-0014.

13. Ortega FX. Displasia del desarrollo de la cadera. Rev Med Clin Condes. 2013; 24(1):37-43.

14. Gentile LF, Ghiragossian D, Blumenthal L, Cozzani H, et al. Ecografía DINÁMICA DE CADERAS: una nueva arma para el pediatra. Arch Argent Pediatr. 1991; 89(4):219-24.

15. AIUM-ACR-SPR-SRU. Practice Parameter for the Performance of an Ultrasound Examination for Detection and Assessment of Developmental Dysplasia of the Hip. J Ultrasound Med. 2018; 37(11):e1-5.
16. Gentile LF. Reflexiones sobreecografía dinámica de cadera. ¿Qué, cómo, quién y cuándo? Arch Argent Pediatr. 1993; 91(8):377-9.

17. Brenes Méndez M, Flores Castro A, Meza Martínez A. Actualización en displasia del desarrollo de la cadera. Rev Med Sinerg. 2020; 5(9):e574.

18. Starr V,HaBY. Imaging update on developmental dysplasia of the hip with the role of MRI. AJR Am J Roentgenol. 2014; 203(6):1324-35.

19. Riccabona M, Schweintzger G, Grill F, Graf R. Screening for developmental hip dysplasia (DDH)- clinically or sonographically? Comments to the current discussion and proposals. Pediatr Radiol. 2013; 43(5):637-40.

20. Rosendahl K, Tomá P. Reply to Riccabona et al. regarding screening for developmental dysplasia of the hip. Pediatr Radiol. 2013; 43(5):641-2.

21. Brañanova López P, Fernández Rey C, López Criado A, Yagüe Zapatero EM, et al. Radiological anatomy of the hip: are we ready to answer the questions of orthopedic surgeons'questions? The European Congress of Radiology ECR 2010.4-8 March 2010. Vienna, Austria. Poster Number C-2277.

22. Clarke N, Reading IC, Corbin C, Taylor C, et al. Twenty years' experience of selective secondary ultrasound screening for congenital dislocation of the hip. Arch Dis Child. 2012; 97(5):423-9.

23. Vaquero-Picado A, González-Morán G, Gil Garay E, Moraleda L. Developmental dysplasia of the hip: update of management. EFORT Open Rev. 2019; 4(9):548-56.

24. Arthurs OJ, van Rijn RR, Granata C, Porto L, et al. European Society of Paediatric Radiology 2019 strategic research agenda: improving imaging for tomorrow's children. Pediatr Radiol. 2019; 49(8):983-9. 